\title{
Self-Reported Psychosocial Health in Obese Patients before and after Weight Loss
}

\author{
G. Osei-Assibey, ${ }^{1}$ I. Kyrou, ${ }^{1}$ S. Kumar, ${ }^{2}$ P. Saravanan, ${ }^{1}$ and K. A. Matyka ${ }^{1}$ \\ ${ }^{1}$ Unit for Diabetes and Metabolism, Clinical Sciences Research Institute, Warwick Medical School, University Hospital Coventry, \\ Clifford Bridge Road, Coventry CV2 2DX, UK \\ ${ }^{2}$ Unit of Diabetes, Endocrinology and Metabolism, University Hospital Coventry, Clifford Bridge Road, Coventry CV2 2DX, UK
}

Correspondence should be addressed to K. A. Matyka, k.a.matyka@warwick.ac.uk

Received 23 June 2009; Revised 23 December 2009; Accepted 10 February 2010

Academic Editor: Eric Doucet

Copyright ( $) 2010$ G. Osei-Assibey et al. This is an open access article distributed under the Creative Commons Attribution License, which permits unrestricted use, distribution, and reproduction in any medium, provided the original work is properly cited.

Psychosocial profiles were examined in 255 morbidly obese patients attending a hospital service offering access to standard weight loss therapies. 129 patients were reassessed after at least 6-month follow-up. At baseline, $51.8 \%$ and $32.7 \%$ of patients, respectively, had evidence of anxiety and depressive disorders, 24\% had severe impairments in self esteem, and $29.7 \%$ had an increased risk of eating disorders. At follow-up, weight loss from baseline was significant in all 3 therapies: diet only is $0.74 \pm 1.8 \mathrm{~kg}$; pharmacotherapy is $6.7 \pm 4.2 \mathrm{~kg}$; and surgery is $20.1 \pm 13.6 \mathrm{~kg}$. Anxiety scores improved in all three groups $(P<.05)$. Patients having pharmacotherapy or surgery had significant improvements in physical and work function and public distress compared to those having dietary treatment only $(P<.05)$. Our observational data suggest that weight management services can lead to psychosocial benefit in morbidly obese patients. Well-designed studies are necessary to examine the link between weight loss and emotional health.

\section{Introduction}

In addition to physical comorbidities such as type 2 diabetes and cardiovascular disease risk factors, obesity may also be associated with alterations in psychosocial health including quality of life, emotional well-being, and eating behaviour: a relationship that is likely to be bidirectional. Studies have indicated that people with higher body mass index (BMI) have poor quality of life [1-3], anxiety and depressive disorders [4], and disordered eating behaviour [5]. A UK study has also found that a third of obese patients in a weight management clinic had severe impairment in quality of life [6], about a quarter demonstrated personality features commonly associated with eating disorders [6], and nearly half of obese patients had anxiety and depressive disorders $[4,6]$.

Obesity has been described as "the last socially acceptable form of prejudice" [7]. Obese people face prejudice and discrimination including being labelled as lazy, dirty, and ugly [8]. Women are less likely to be married or complete schooling/education, achieve a lower income than nonoverweight females despite comparable intellectual aptitudes [9], and experience job discrimination [10, 11]. Wadden et al. [12] have suggested that given the prejudice and discrimination that obese people endure, it would not be surprising to discover that they experience greater psychological distress than nonobese peers, and this appears to be the case with individuals seeking weight reduction. However the relationship between overweight/obesity and psychosocial health is likely to be complex. Weight loss does not always improve quality of life [13-19], mood [14], and eating behaviour $[13,20]$. In addition motivation and adherence to a weight management plan may/may not be affected by the presence of mood, eating disorders, and poor quality of life $[6,21-23]$.

Specialist weight management clinics are being developed all over the U.K, but there is little or no evidence in the UK on either the positive or even negative consequences of attending such services. We present an observational study to describe (i) baseline self-reported psychosocial health in 
obese patients and (ii) followup changes in psychosocial health after weight management.

\section{Patients and Methods}

Obese patients attending a specialist secondary clinic at the Warwick Institute for the Study of Diabetes, Endocrinology and Metabolism (WISDEM), at the University Hospital Coventry were followed up (January to July 2008) for this study. At WISDEM, initial/baseline clinical assessments performed included weight, height and BMI, and obesity-related physical and psychosocial comorbidity identification. Based on initial clinical assessments, patients had dietary counselling with/without psychological counselling (with sessions every 4-6 months) or dietary counselling with antiobesity medication (sibutramine and orlistat) with/without psychological counselling or dietary counselling and bariatric surgery (gastric lapband) with/without psychological counselling.

Patients were morbidly obese with a mean BMI of $46.5 \pm$ $8.1 \mathrm{~kg} / \mathrm{m}^{2}$. All patients $(n=255)$ had healthy eating and lifestyle advice which consisted of dietary counselling on a list of recommended foods and recipes, portions and combinations, and were encouraged to engage in moderate physical activity of their choice for at least 30 minutes a day. There was also advice on calorie counting, weekly menu planning, and advice for those on low-fat or low carbohydrate diets by a qualified dietician.

One hundred and 57 patients received dietary therapy only (with or without psychological counselling, see below). Pharmacotherapy for weight loss was offered to 71 patients who needed immediate weight loss for medical reasons (such as patients with diabetes and cardiovascular disease risk) (sibutramine), and patients with elevated LDL cholesterol values or impaired glucose tolerance, and who had the ability to adhere to a low-fat diet for a long period (orlistat) (Figure 1).

Twenty-seven patients with a BMI $\geq 40 \mathrm{~kg} / \mathrm{m} 2$ and significant obesity-related illness or demonstrated history of unsuccessful weight loss by medical management and with no alcohol disorder, no drug dependence, and no history of psychiatric illness had bariatric surgery (gastric banding).

In addition, psychological counselling was offered to patients who were identified from the initial assessments to be at risk of disordered eating behaviour (EAT scores $>20$ ) and obesity-related depression currently or in the past by a clinical psychologist.

The study had ethical approval from Coventry Local Research Ethics Committee (CREC). Information sheets, 2 consent forms, and questionnaires were sent to patients prior to their followup appointment at WISDEM, to complete and bring with them to their appointment. In addition any patients who needed more information or clarification were contacted by a member of the research team by telephone.

\section{Assessments}

3.1. Anthropometry. Baseline and followup weight was measured using Seca 665 Wheelchair scale to the nearest $0.5 \mathrm{~kg}$.
This is an electronic scale with a capacity of $300 \mathrm{~kg}$, hence its suitability for morbidly obese patients. The Harpenden stadiometer was used to measure height to the nearest $0.1 \mathrm{~m}$, and BMI was calculated using the formula; weight $\div$ (height) $)^{2}$.

3.2. Emotional/Mental Well-Being. Hospital anxiety and depression scale (HADS) was developed to assess mood disorder, especially anxiety and depression in and outside hospital and community settings. HADS consists of 14 questions, 7 for anxiety (marked "A") and 7 for depression (marked "D"). Scores of 0-7 in respective subscales are considered normal, 8-10 is suggestive of the presence of disorder, and $\geq 11$ indicates the probable presence of disorder [24, 25]. For the purposes of this study a value of $\geq 11$ was used as the criterion for the presence of anxiety or depressive disorders [24].

3.3. Quality of Life. Impact of weight on quality of life (IWQoL-Lite) is a validated 31 item, self report measure of obesity-specific quality of life. It is made up of scores on five domains/subscales: Physical Function (11 items), Selfesteem (7 items), Sexual life (4 items), Public Distress (5 items), and work (4 items). All items in IWQol-Lite are rated from 5 (always true) to 1 (never true) [14, 15]. Subscale scores are obtained by adding item scores and transformed to a range of 0 to 100 . Higher scores indicate poor quality of life $[3,14,15]$. For the purposes of this paper, scores of $>90$ indicated severe/marked impairment in quality of life [6].

3.4. Eating Attitude Test (EAT-26). EAT-26 alone does not diagnose an eating disorder but is a useful tool for assessing "risk of disordered eating behaviour" [26]. Responses are scored as 3 (always) to 0 (rarely) for items 1 to 25 and 0 (always) to 3 (never) for item 26. A score of 20 or more indicates high concerns about body weight, body shape, and eating (risk of disordered eating behaviour). A score of $<20$ indicates low concerns about body weight, body shape, and eating [26]. Although originally designed to screen for risk of disordered eating behaviour in nonobese populations the EAT-26 has previously been used in studies of obese adults. Although lower cut-offs for eating disorder risk have been suggested for this group of patients who may be considered at high risk, the "standard" cut-off of 20 was used for this study as access to psychological services was limited [27].

3.5. Data and Statistical Analysis. Data and statistical analyses were performed using SPSS version 14.0. All data are expressed as mean \pm standard deviation. Parametric tests used included independent $t$-tests, analysis of variance with posthoc Bonferroni testing. Nonparametric methods used included the Mann-Whitney $U$-test. Followup results were analysed for each therapy based on subgroups of patients receiving psychological counselling.

\section{Results}

4.1. Baseline. A total of 255 obese patients (75 men and 180 women) were attending the clinic at WISDEM in 


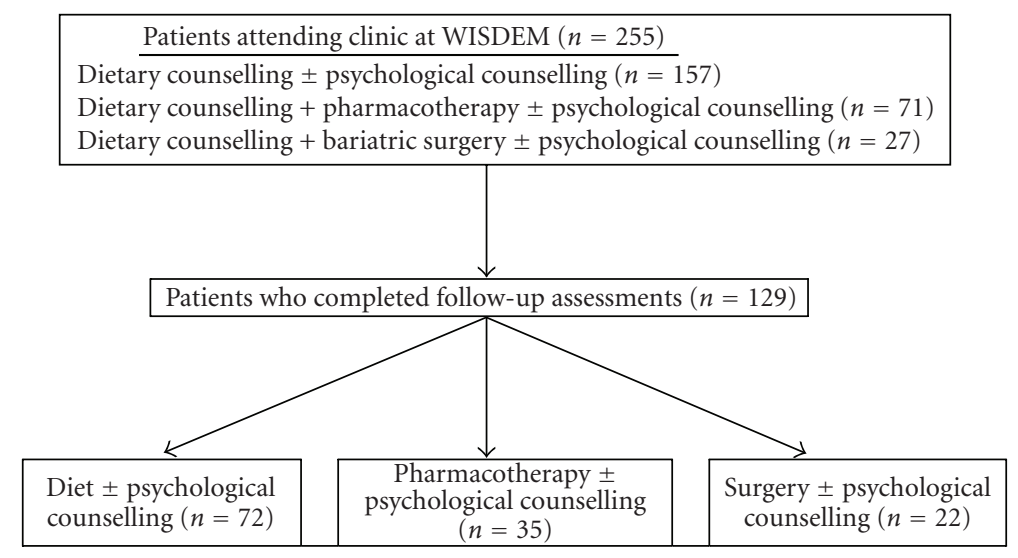

FIgURE 1: Study profile.

January 2008 (Table 1). All patients were morbidly obese (mean BMI $46.5 \pm 8.1 \mathrm{~kg} / \mathrm{m}^{2}$ ). About $85 \%$ of patients were White Europeans and the rest nonwhites (South Asians and Blacks). About a third (29\%) of patients had type 2 diabetes, with/without raised blood pressure and cholesterol.

About fifty two percent (51.8\%) and $32.7 \%$ of patients, respectively, had presence of anxiety and depressive disorders (HADS score $>11$ for either anxiety or depression). Women were significantly more likely to be categorised as having an anxiety disorder than men $(52.3 \%$ versus $38.9 \%$, resp., $P=$ .032 ), but no significant difference was found in depression. Variable impairments in quality of life from the five subscales of the IWQoL-Lite were identified. Severe impairments, defined as a score of $>90$, were seen in $24 \%$ of patients with respect to self esteem and $22 \%$ with respect to their sexual life. There were gender differences and the proportion of women who had severe impairment in quality of life was significantly higher than men in self esteem $(30.1 \%$ versus $10.0 \%$, resp., $P=.020)$ and sexual life (26\% versus $14.5 \%$, resp., $P=.031$ ).

About a third $(29.7 \%)$ of all patients were at risk of disordered eating behaviour (EAT26 score $>20$ ). Women were significantly more likely to be at risk of disordered eating behaviour than men $(35.9 \%$ versus $14.5 \%$, resp., $P=$ $.033)$.

4.2. Follow-Up. A hundred and twenty nine ( 89 women and 40 men) patients completed and returned questionnaires for the followup study (Table 2). Of these, 72 had dietary therapy alone, 35 had dietary therapy and pharmacotherapy (sibutramine or orlistat), and 22 had dietary therapy and bariatric surgery (gastric lapband). Weight loss was significant from baseline in patients who had dietary therapy $(-0.74 \pm 1.8, P=.004)$, pharmacotherapy $(-6.7 \pm 4.2 \mathrm{~kg}$, $P<.001)$ and bariatric surgery $(-20.1 \pm 13.5 \mathrm{~kg}, P<.001)$, (Table 2 ). In addition, a total of 38 patients $(29.5 \%)$ (18 on pharmacotherapy and 20 who underwent bariatric surgery) achieved $\geq 5 \%$ weight loss.

All three therapies resulted in a significant reduction in anxiety scores from baseline with no significant difference between therapies. However, using Mann-Whitney U-test to detect differences between any two therapy groups, reductions in depressive scores, physical function, public distress, and work function were significantly higher in pharmacotherapy $(P<.05)$ and bariatric surgery $(P<.05)$ compared with dietary therapy (Table 2).

\section{Discussion}

About $15 \%$ of the baseline patients were from nonwhite ethnic minorities reflecting the ethnic/population demography of Coventry and Warwickshire [28]. Two-and-half times as many women were attending the weight management clinic as men, an indication that women are

more likely to make hospital appointments than men [29, 30], and probably more likely to seek help for weight control than men due to greater concerns and societal pressure with appearance, body shape, and health [31]. However the larger number of women than men contrasts with evidence which suggests that the U.K is one of few countries where obesity is greater among men than among women [32].

The significantly higher proportion of women with anxiety disorders than men at baseline is similar to that obtained by Tuthill et al. [6] in obese patients attending a weight management clinic in Cambridgeshire in the U.K. It has been suggested that in the West, women are more likely to express and seek treatment for their anxiety than men [33]. However the nonsignificant difference in depressive disorders between the genders at baseline differs from what pertains in the general population, where twice as many women as men have depressive disorders [34, 35].

At baseline women had significant impairment in weight related self esteem than men as assessed by the IWQoL-Lite subscale. Gender differences in self esteem are well described in the literature. Self-esteem is positively related to body satisfaction $[36,37]$, and women tend to have more negative assessments of their physical characteristics than men, and hence lower self-esteem [38-40].

The significantly higher proportion of women with risk of disordered eating behaviour than men at baseline is supported by evidence in the literature. The EAT26 questionnaire is the most widely used standardised questionnaire to 
TABLE 1: Baseline results (mean $\pm \mathrm{sd}$ ) and proportion (\%) of patients with psychosocial disorders.

\begin{tabular}{|c|c|c|c|}
\hline & All patients $(n=255)$ & Men $(n=75)$ & Women $(n=180)$ \\
\hline Age (years) & $46.8 \pm 11.8$ & $46.6 \pm 12.6$ & $46.8 \pm 11.5$ \\
\hline Weight (kg) & $132.3 \pm 27.5$ & $143.6 \pm 29.1$ & $127.5 \pm 25.4$ \\
\hline BMI $\left(\mathrm{kg} / \mathrm{m}^{2}\right)$ & $46.5 \pm 8.1$ & $46.0 \pm 8.1$ & $46.7 \pm 8.1$ \\
\hline \multicolumn{4}{|l|}{ HADS } \\
\hline Anxiety & $9.5 \pm 4.8(51.8 \%)$ & $8.4 \pm 4.7(38.9 \%)$ & $10.0 \pm 4.8(52.3 \%)$ \\
\hline Depression & $8.5 \pm 4.7(32.7 \%)$ & $8.1 \pm 4.5(33.9 \%)$ & $8.6 \pm 4.7(42.4 \%)$ \\
\hline \multicolumn{4}{|l|}{ IWQoL-Lite } \\
\hline Physical function & $63.2 \pm 24.3(18.3 \%)$ & $60.6 \pm 25.2(13.1 \%)$ & $64.2 \pm 23.9(20.4 \%)$ \\
\hline Self esteem & $65.2 \pm 28.8(24.1 \%)$ & $58.6 \pm 29.1(10.0 \%)$ & $67.9 \pm 28.4(30.1 \%)$ \\
\hline Sexual life & $55.6 \pm 34.8(22.6 \%)$ & $52.3 \pm 33.8(14.5 \%)$ & $57.0 \pm 35.2(26.0 \%)$ \\
\hline Public distress & $58.2 \pm 30.6(16.1 \%)$ & $54.6 \pm 34.2(16.7 \%)$ & $59.6 \pm 28.9(15.9 \%)$ \\
\hline Work function & $45.8 \pm 29.9(10.4 \%)$ & $47.1 \pm 31.6(37.3 \%)$ & $45.4 \pm 29.4(10.9 \%)$ \\
\hline EAT-26 & $15.1 \pm 10.0(29.7 \%)$ & $12.2 \pm 8.2(14.5 \%)$ & $16.3 \pm 10.5(35.9 \%)$ \\
\hline
\end{tabular}

TABLE 2: Follow-up changes (mean $\pm s d$ ).

\begin{tabular}{|c|c|c|c|c|c|c|c|c|c|}
\hline & \multicolumn{3}{|c|}{ Dietary therapy alone $(n=72)$} & \multicolumn{3}{|c|}{ Pharmacotherapy $(n=35)$} & \multicolumn{3}{|c|}{ Bariatric surgery $(n=22)$} \\
\hline & $\begin{array}{c}\text { Total } \\
(n=72)\end{array}$ & $\begin{array}{c}\text { Psych. } \\
\text { counselling } \\
(n=35)\end{array}$ & $\begin{array}{l}\text { No psych. } \\
\text { counselling } \\
(n=37)\end{array}$ & $\begin{array}{c}\text { Total } \\
(n=35)\end{array}$ & $\begin{array}{c}\text { Psych. } \\
\text { counselling } \\
(n=15)\end{array}$ & $\begin{array}{l}\text { No psych. } \\
\text { counselling } \\
(n=20)\end{array}$ & $\begin{array}{c}\text { Total } \\
(n=22)\end{array}$ & $\begin{array}{c}\text { Psych. } \\
\text { counselling } \\
(n=10)\end{array}$ & $\begin{array}{l}\text { No psych. } \\
\text { counselling } \\
(n=13)\end{array}$ \\
\hline Weight, kg & $\begin{array}{l}-0.74 \\
\pm 1.8^{\mathrm{a}}\end{array}$ & $-0.83 \pm 1.5$ & $-0.63 \pm 2.1$ & $-6.7 \pm 4.2^{\mathrm{a}}$ & $-5.3 \pm 2.8$ & $-8.8 \pm 5.1^{\mathrm{b}}$ & $\begin{array}{l}-20.1 \\
\pm 13.6^{a}\end{array}$ & $-16.1 \pm 8.3$ & $\begin{array}{c}-25.7 \pm \\
17.8\end{array}$ \\
\hline \multicolumn{10}{|l|}{ HADS } \\
\hline anxiety & $-2.8 \pm 4.3^{\mathrm{a}}$ & $-4.2 \pm 3.9^{b}$ & $-0.3 \pm 3.9$ & $-2.6 \pm 4.4^{\mathrm{a}}$ & $-4.5 . \pm 4.1^{\mathrm{b}}$ & $0.8 \pm 2.3$ & $-4.2 \pm 4.1^{\mathrm{a}}$ & $-4.3 \pm 4.8$ & $-3.8 \pm 1.5$ \\
\hline Depression & $-1.4 \pm 5.1$ & $-3.1 \pm 4.3^{\mathrm{b}}$ & $1.8 \pm 4.8$ & $\begin{array}{c}-2.6 \\
\pm 4.3^{\mathrm{a}, \mathrm{c}}\end{array}$ & $-4.7 \pm 3.3^{\mathrm{b}}$ & $0.7 \pm 3.6$ & $\begin{array}{c}-2.3 \\
\pm 4.4^{\mathrm{a}, \mathrm{d}}\end{array}$ & $-2.4 \pm 4.9$ & $-2.2 \pm 3.6$ \\
\hline \multicolumn{10}{|l|}{ IWQoL } \\
\hline $\begin{array}{l}\text { Physical } \\
\text { function }\end{array}$ & $\begin{array}{l}-12.8 \\
\pm 25.6^{\mathrm{a}}\end{array}$ & $-15.7 \pm 28.1$ & $-7.7 \pm 20.3$ & $\begin{array}{c}-26.6 \\
\pm 26.2^{\mathrm{a}, \mathrm{c}}\end{array}$ & $\begin{array}{r}-33.3 \\
\pm 23.7^{\mathrm{b}}\end{array}$ & $-13.1 \pm 26.8$ & $\begin{array}{c}-32.9 \\
\pm 24.7^{\mathrm{a}, \mathrm{d}}\end{array}$ & $-25.1 \pm 23.9$ & $\begin{array}{c}-46.5 \pm \\
21.4\end{array}$ \\
\hline Self esteem & $\begin{array}{l}-13.6 \\
\pm 34.9^{\mathrm{a}}\end{array}$ & $\begin{array}{l}-21.2 \\
\pm 32.6^{\mathrm{b}}\end{array}$ & $0.6 \pm 35.6$ & $\begin{array}{l}-27.7 \\
\pm 26.7^{\mathrm{a}}\end{array}$ & $\begin{array}{l}-34.7 \\
\pm 24.8^{\mathrm{b}}\end{array}$ & $-13.7 \pm 25.8$ & $\begin{array}{c}-15.3 \pm \\
39.0\end{array}$ & $-11.9 \pm 46.6$ & $\begin{array}{c}-21.2 \pm \\
22.7\end{array}$ \\
\hline Sexual life & $\begin{array}{l}-11.5 \\
\pm 31.3^{\mathrm{a}}\end{array}$ & $\begin{array}{r}-17.9 \\
\pm 33.9^{b}\end{array}$ & $4.3 \pm 33.9$ & $\begin{array}{l}-20.2 \\
\pm 23.6^{\mathrm{a}}\end{array}$ & $\begin{array}{r}-28.3 \\
\pm 21.2^{\mathrm{b}}\end{array}$ & $-3.1 \pm 19.4$ & $\begin{array}{c}-12.9 \pm \\
40.3\end{array}$ & $-3.8 \pm 41.2$ & $\begin{array}{c}-29.2 \pm \\
37.2\end{array}$ \\
\hline $\begin{array}{l}\text { Public } \\
\text { distress }\end{array}$ & $\begin{array}{c}-10.9 \pm \\
37.5\end{array}$ & $-13.3 \pm 36.9$ & $-6.3 \pm 39.3$ & $\begin{array}{c}-21.4 \\
\pm 33.3^{\mathrm{a}, \mathrm{c}}\end{array}$ & $\begin{array}{r}-32.1 \\
\pm 33.1^{\mathrm{b}}\end{array}$ & $-0.2 \pm 22.5$ & $\begin{array}{c}-22.7 \\
\pm 27.9^{\mathrm{a}, \mathrm{d}}\end{array}$ & $-13.9 \pm 29.6$ & $\begin{array}{c}-37.8 \pm \\
17.8\end{array}$ \\
\hline $\begin{array}{r}\text { Work } \\
\text { function }\end{array}$ & $\begin{array}{l}-3.7 \pm \\
29.7\end{array}$ & $-7.7 \pm 29.8$ & $3.7 \pm 29.1$ & $\begin{array}{c}-14.9 \\
\pm 23.8^{\mathrm{a}, \mathrm{c}}\end{array}$ & $\begin{array}{l}-22.4 \\
\pm 21.5^{b}\end{array}$ & $1.8 \pm 20.6$ & $\begin{array}{l}-14.3 \\
\pm 30.8^{\mathrm{d}}\end{array}$ & $-11.8 \pm 35.2$ & $\begin{array}{c}-18.6 \pm \\
23.6\end{array}$ \\
\hline EAT & $-1.1 \pm 9.6$ & $-3.8 \pm 8.7^{\mathrm{b}}$ & $4.4 \pm 9.1$ & $\begin{array}{r}-3.9 \\
\pm 10.8^{\mathrm{a}} \\
\end{array}$ & $-6.7 \pm 10.9^{b}$ & $1.5 \pm 8.7$ & $-1.4 \pm 8.3$ & $-2.9 \pm 8.9$ & $2.0 \pm 5.9$ \\
\hline
\end{tabular}

$\mathrm{a}=$ significant change from baseline. $(P<.05)$,

$\mathrm{b}=$ significant difference $(P<.05)$ between psychological versus no psychological counselling.

${ }^{c}=P<.05$ pharmacotherapy versus dietary therapy alone.

$\mathrm{d}=P<.05$ bariatric surgery versus dietary therapy alone.

assess risk of disordered eating and had mainly been used in populations of nonobese subjects. Data from the use of this questionnaire in studies of obese adults suggest that the cutoff for definition may need to be adjusted and may even need to be lower. Although our results were obtained from morbidly obese patients attending weight management, results from the general population suggest that every fourth female adolescent perceives herself as fat or overweight, regardless of being normal weight, whilst the number of male adolescents with the same perception is one-quarter to one-half the number of females; so our results do not seem unrealistic $[41,42]$. It has been suggested that the stress of perceiving oneself as overweight may push females to unhealthy eating behaviours [43]. In contrast, others have suggested that males under-report disordered eating behaviours as they are considered to be very specific to the female gender [44].

Results at follow-up showed improvements in quality of life, emotional well being, and disordered eating behaviour. Some patients also achieved significant weight loss; however 
the observational nature of this study precludes us from correlating weight loss and change in psychosocial status. A number of other factors may influence these outcomes in a clinical setting. Some of the patients were offered psychological counselling which may have led to improvements irrespective of weight loss. In addition patients are provided with a reasonable amount of care and support through attending a specialist weight service which also may have beneficial effects on emotional health.

Although this study has thrown some light on selfreported psychosocial health in obese patients and changes after weight loss, the limitations inherent in all observational studies (noncontrolled, hence prone to confounding) remain. The study was not significantly powered at follow-up and therefore might not have detected significant changes in psychosocial health. Finally psychosocial data were obtained from self report questionnaires which suffer from limitations including (i) respondents unwillingness to report behaviours which may be considered undesirable, (ii) respondents inability to mentally score their behaviours and feelings over time, and (iii) self-report questionnaires require good reading and understanding skills which can be difficult to ascertain in clinical patients.

In summary, these data suggest that improvements in psychosocial variables can be seen in patients attending a weight loss service provided in secondary care. The management of any person with a chronic condition results in an interplay of a multiplicity of factors of which environment, personnel, and treatment modalities are but a few. Therefore larger randomised controlled studies are needed to evaluate the complex relationships between obesity, weight loss, and psychosocial health.

\section{References}

[1] R. L. Kolotkin, R. D. Crosby, K. D. Kosloski, and G. R. Williams, "Development of a brief measure to assess quality of life in obesity," Obesity Research, vol. 9, no. 2, pp. 102-111, 2001.

[2] R. L. Kolotkin, R. D. Crosby, and G. R. Williams, "Healthrelated quality of life varies among obese subgroups," Obesity Research, vol. 10, no. 8, pp. 748-756, 2002.

[3] M. A. White, P. M. O’Neil, R. L. Kolotkin, and T. K. Byrne, "Gender, race, and obesity-related quality of life at extreme levels of obesity," Obesity Research, vol. 12, no. 6, pp. 949-955, 2004.

[4] T. A. Wadden, D. B. Sarwer, L. G. Womble, G. D. Foster, B. G. McGuckin, and A. Schimmel, "Psychosocial aspects of obesity and obesity surgery," Surgical Clinics of North America, vol. 81, no. 5, pp. 1001-1024, 2001.

[5] F. Bernardi, C. Cichelero, and M. R. Vitolo, "Restrained eating behavior and obesity," Revista de Nutricao, vol. 18, no. 1, pp. 85-93, 2005.

[6] A. Tuthill, H. Slawik, S. O'Rahilly, and N. Finer, "Psychiatric co-morbidities in patients attending specialist obesity services in the UK," QJM, vol. 99, no. 5, pp. 317-325, 2006.

[7] J. Sobal and A. J. Stunkard, "Socioeconomic status and obesity: a review of the literature," Psychological Bulletin, vol. 105, no. 2, pp. 260-275, 1989.

[8] J. R. Staffieri, "A study of social stereotype of body image in children," Journal of Personality and Social Psychology, vol. 7, no. 1, pp. 101-104, 1967.
[9] S. L. Gortmaker, A. Must, J. M. Perrin, A. M. Sobol, and W. H. Dietz, "Social and economic consequences of overweight in adolescence and young adulthood," The New England Journal of Medicine, vol. 329, no. 14, pp. 1008-1012, 1993.

[10] I. H. Frieze, J. E. Olson, and D. C. Good, "Perceived and actual discrimination in the salaries of male and female managers," Journal of Applied and Social Psychology, vol. 20, pp. 46-67, 1990.

[11] R. Pingitore, B. L. Dugoni, R. S. Tindale, and B. Spring, "Bias against overweight job applicants in a simulated employment interview," Journal of Applied Psychology, vol. 79, no. 6, pp. 909-917, 1994.

[12] T. A. Wadden, L. G. Womble, A. J. Stunkard, and D. A. Anderson, "Psychosocial consequences of obesity and weight loss," in Handbook of Obesity Treatment, T. A. Wadden and A. J . Stunkard, Eds., pp. 144-169, Guilford Press, New York, NY, USA, 2002.

[13] J. Karlsson, L. Sjöström, and M. Sullivan, "Swedish obese subjects (SOS) —an intervention study of obesity. Two-year follow-up of health-related quality of life (HRQL) and eating behavior after gastric surgery for severe obesity," International Journal of Obesity, vol. 22, no. 2, pp. 113-126, 1998.

[14] R. L. Kolotkin, R. D. Crosby, G. R. Williams, G. G. Hartley, and S. Nicol, "The relationship between health-related quality of life and weight loss," Obesity Research, vol. 9, no. 9, pp. 564$571,2001$.

[15] R. L. Kolotkin and R. D. Crosby, "Psychometric evaluation of the impact of weight on quality of life-lite questionnaire (IWQOL-Lite) in a community sample," Quality of Life Research, vol. 11, no. 2, pp. 157-171, 2002.

[16] J. B. Dixon and P. E. O'Brien, "Changes in comorbidities and improvements in quality of life after LAP-BAND placement," American Journal of Surgery, vol. 184, no. 6, supplement 2, pp. 51S-54S, 2002.

[17] N. Barreto Villela, O. Braghrolli Neto, K. Lima Curvello, et al., "Quality of life of obese patients submitted to bariatric surgery," Nutricion Hospitalaria, vol. 19, no. 6, pp. 367-371, 2004.

[18] L. F. van Gaal, A. M. Rissanen, A. J. Scheen, O. Ziegler, and S. Rössner, "Effects of the cannabinoid-1 receptor blocker rimonabant on weight reduction and cardiovascular risk factors in overweight patients: 1-year experience from the RIO-Europe study," The Lancet, vol. 365, no. 9468, pp. 13891397, 2005.

[19] S. G. Engel, R. D. Crosby, R. L. Kolotkin, et al., "Impact of weight loss and regain on quality of life: mirror image or differential effect?" Obesity Research, vol. 11, no. 10, pp. 12071213, 2003.

[20] A. J. Stunkard, "Binge-eating disorder and the night-eating syndrome," in Handbook of Obesity Treatment, T. A. Wadden and A. J. Stunkard, Eds., pp. 107-121, Guilford Press, New York, NY, USA, 2002.

[21] V. Hainer, M. Kunesova, F. Bellisle, et al., "Psychobehavioral and nutritional predictors of weight loss in obese women treated with sibutramine," International Journal of Obesity, vol. 29, no. 2, pp. 208-216, 2005.

[22] P. J. Teixeira, S. B. Going, L. B. Houtkooper, et al., "Pretreatment predictors of attrition and successful weight management in women," International Journal of Obesity, vol. 28, no. 9, pp. 1124-1133, 2004.

[23] J. A. Linde, R. W. Jeffery, R. L. Levy, et al., "Binge eating disorder, weight control self-efficacy, and depression in overweight men and women," International Journal of Obesity, vol. 28, no. 3, pp. 418-425, 2004. 
[24] A. S. Zigmond and R. P. Snaith, "The hospital anxiety and depression scale," Acta Psychiatrica Scandinavica, vol. 67, no. 6, pp. 361-370, 1983.

[25] R. P. Snaith, "The hospital anxiety and depression scale," Health and Quality of Life Outcomes, vol. 1, article 29, 2003.

[26] D. M. Garner, M. P. Olmsted, Y. Bohr, and P. E. Garfinkel, "The eating attitudes test: psychometric features and clinical correlates," Psychological Medicine, vol. 12, no. 4, pp. 871-878, 1982.

[27] B. Orbitello, R. Ciano, M. Corsaro, et al., "The EAT-26 as screening instrument for clinical nutrition unit attenders," International Journal of Obesity, vol. 30, no. 6, pp. 977-981, 2006.

[28] D. Owen, "The ethnic composition of Coventry," National Ethnic Minority Data Archive Information Paper 95/2, http:// www.warwick.ac.uk/ errac/coventry.pdf.

[29] J. Harrison, P. Maguire, and C. Pitceathly, "Confiding in crisis: gender differences in pattern of confiding among cancer patients," Social Science and Medicine, vol. 41, no. 9, pp. 12551260, 1995.

[30] G. M. Leydon, M. Boulton, C. Moynihan, A. Jones, J. Mossman, and M. Boudioni, "Cancer patients' information needs and information seeking behavior: in depth interview study," British Medical Journal, vol. 320, pp. 909-913, 2000.

[31] J. Fiala and Z. Brázdová, "A comparison between the lifestyles of men and women-parents of school age children," Central European Journal of Public Health, vol. 8, no. 2, pp. 94-100, 2000.

[32] World Health Organisation Consultation on Obesity, "Preventing and managing the global Epidemic. Report of a WHO consultation," WHO Technical Report Series 894, WHO, 2000.

[33] Consumer Health Information Network, "Anxiety and anxiety disorders for women," July 2008, http://www.netwellness.org/ healthtopics/women/anxiety.cfm.

[34] M. M. Weissman and G. L. Klerman, "Sex differences and the epidemiology of depression," Archives of General Psychiatry, vol. 34, no. 1, pp. 98-111, 1977.

[35] L. R. Olsen, E. L. Mortensen, and P. Bech, "Prevalence of major depression and stress indicators in the Danish general population," Acta Psychiatrica Scandinavica, vol. 109, no. 2, pp. 96-103, 2004.

[36] W. D. Russell, "Comparison of self-esteem, body satisfaction, and social physique anxiety across males of different exercise frequency and racial back-ground," Journal of Sport Behavior, vol. 25, pp. 74-90, 2002.

[37] S. D. Hayes, P. R. E. Crocker, and K. C. Kowalski, "Gender differences in physical self-perception of global self-esteem, and physical activity: evaluation of the physical self-perception profile model," Journal of Sport Behavior, vol. 22, pp. 1-14, 1999.

[38] A. Furnham, N. Badmin, and I. Sneade, "Body image dissatisfaction: gender differences in eating attitudes, self-esteem, and reasons for exercise," The Journal of Psychology, vol. 136, no. 6, pp. 581-596, 2002.

[39] T. J. Wade and M. Cooper, "Sex differences in the links between attractiveness, self-esteem and the body," Personality and Individual Differences, vol. 27, no. 6, pp. 1047-1056, 1999.

[40] A. Kearney-Cooke, "Gender differences and self-esteem," The Journal of Gender-Specific Medicine, vol. 2, no. 3, pp. 46-52, 1999.

[41] J. Croll, D. Neumark-Sztainer, M. Story, and M. Ireland, "Prevalence and risk and protective factors related to disordered eating behaviors among adolescents: relationship to gender and ethnicity," Journal of Adolescent Health, vol. 31, no. 2, pp. 166-175, 2002.

[42] R. Kaltiala-Heino, S. Kautiainen, S. M. Virtanen, A. Rimpelä, and M. Rimpelä, "Has the adolescents' weight concern increased over 20 years?" European Journal of Public Health, vol. 13, no. 1, pp. 4-10, 2003.

[43] D. L. Braun, S. R. Sunday, A. Huang, and K. A. Halmi, "More males seek treatment for eating disorders," International Journal of Eating Disorders, vol. 25, no. 4, pp. 415-424, 1999.

[44] C. B. Anderson and C. M. Bulik, "Gender differences in compensatory behaviors, weight and shape salience, and drive for thinness," Eating Behaviors, vol. 5, no. 1, pp. 1-11, 2004. 


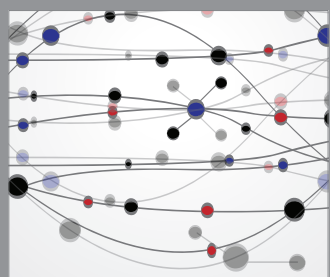

The Scientific World Journal
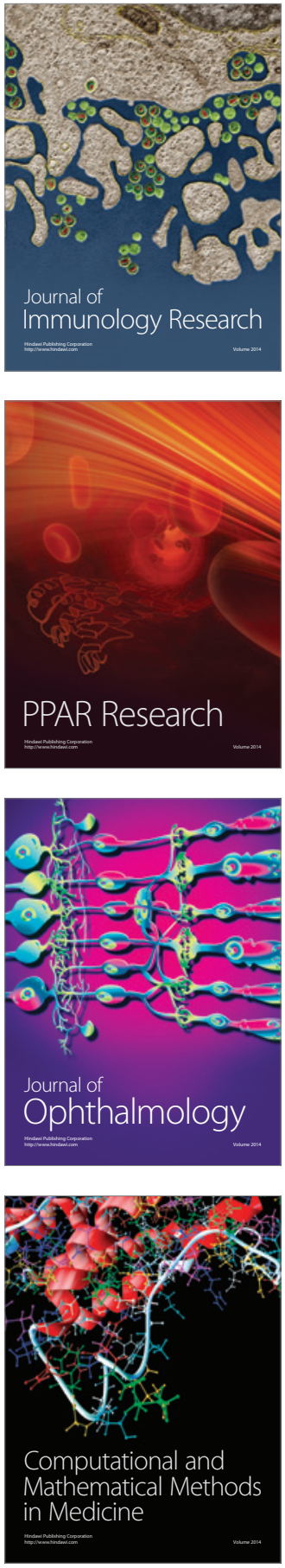

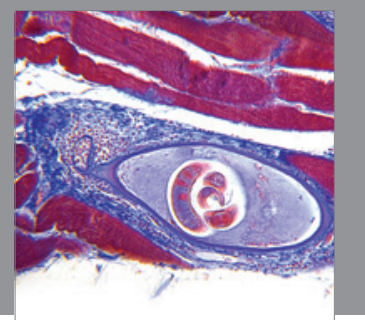

Gastroenterology

Research and Practice


\section{Hindawi}

Submit your manuscripts at

http://www.hindawi.com
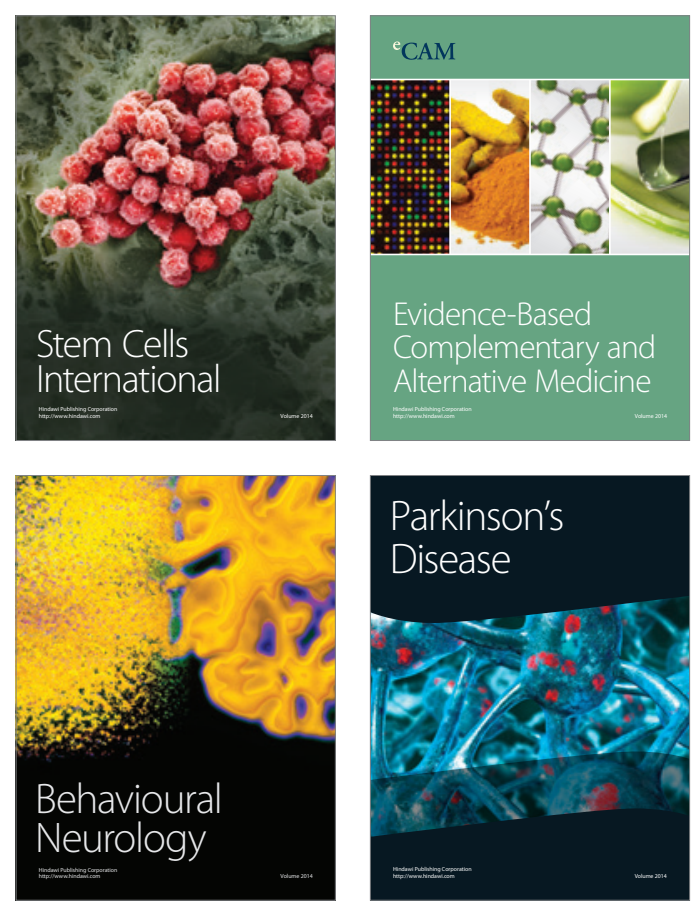

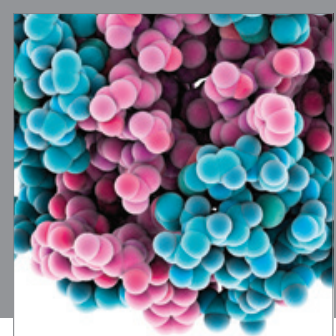

Journal of
Diabetes Research



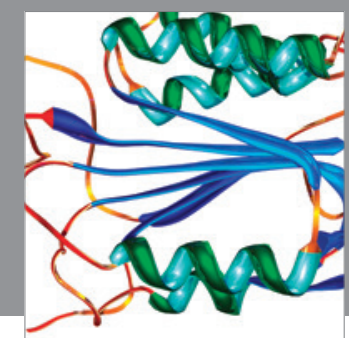

Disease Markers
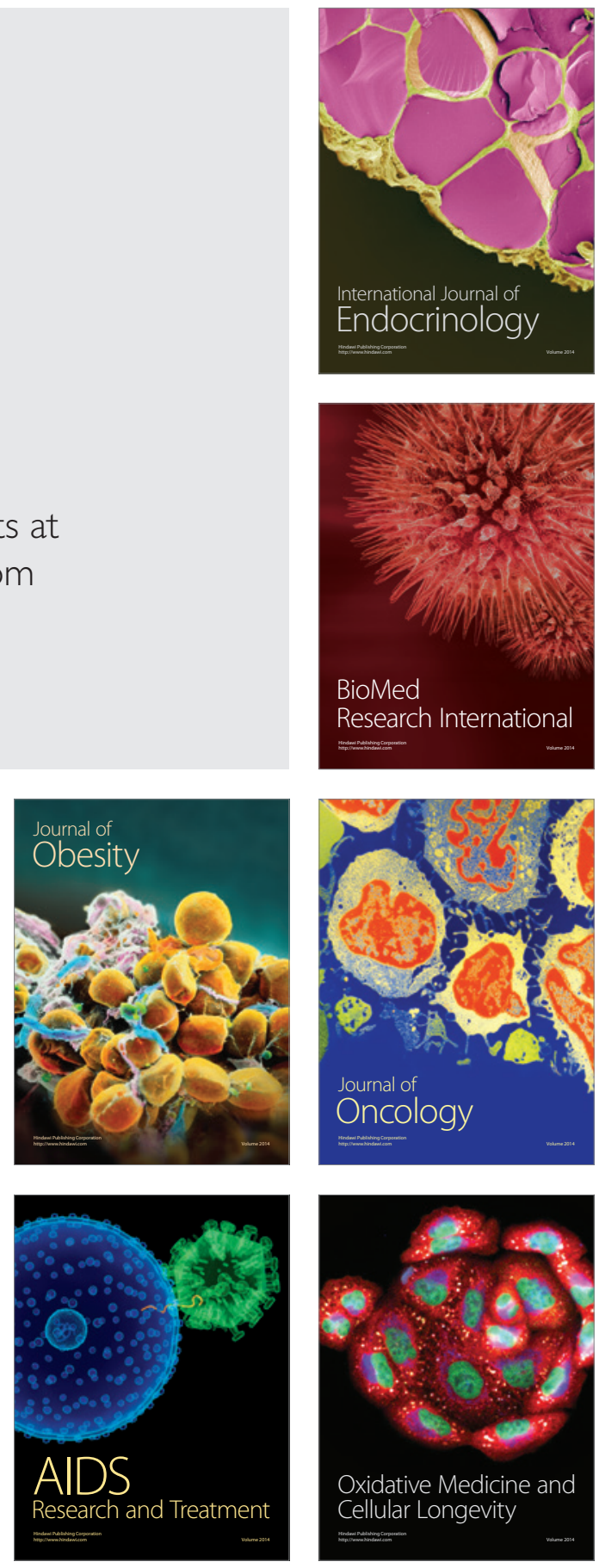